\title{
Plasma interleukin-17 and alpha-fetoprotein combination effectively predicts imminent hepatocellular carcinoma occurrence in liver cirrhotic patients
}

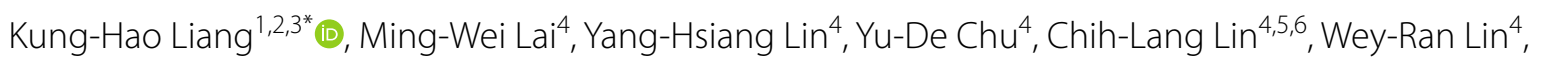
Ya-Hui Huang ${ }^{4}$, Tong-Hung Wang ${ }^{4,7}$, Rong-Nan Chien ${ }^{4,5}$, Tsung-Hui Hu ${ }^{8}$ and Chau-Ting Yeh ${ }^{4,9,10^{*}}$

\begin{abstract}
Background: Predicting imminent hepatocellular carcinoma (HCC) in liver cirrhotic patients is an unmet medical need. We aimed to investigate circulatory biomarkers and their optimum combinations in a prospective study.

Methods: We investigated plasma interleukin 17 (IL-17) concentrations, quantified using enzyme-linked immunosorbent assay (ELISA), for the prediction of HCC in a large cohort of 404 HCC-naïve liver cirrhotic patients regularly followed after recruitment. Additionally, IL-17 in surgically resected tumor tissues were evaluated using immunohistochemistry staining.

Results: IL-17 was detected in HCC tissues. The IL-17 concentrations in the peripheral blood do not have correlation with an extensive list of 31 common demographic, metabolic and liver function variables in the cohort of liver cirrhotic patients. Furthermore, patients stratified by IL-17 and alpha-fetoprotein (AFP) showed distinctive cumulative incidence of HCC. Imminent HCC, defined here as HCC occurrence within 1 year, can be predicted by IL-17 alone with an area under the receiver operating characteristic curve $[A U C]$ of $0.762(P=0.002)$. An multivariate analysis showed that age, hepatitis $C$ viral infection, AFP and IL-17 were four independent factors associated with imminent HCC (adjusted $P=0.03,0.041,0.024$ and 0.008 respectively). An explicit risk score (R) combining the concentrations of two plasma biomarkers, AFP and IL-17, achieved a high AUC of 0.933 (95\% confidence interval $0.893-0.972, P<0.001$ ) in predicting imminent HCC, with $100 \%$ sensitivity and $79.9 \%$ specificity at the optimum cutoff. The score is defined as: $\mathrm{R}=(2.6914) * \mathrm{IL}-17+(0.3909) * \mathrm{AFP}-(0.80812875) * \mathrm{IL}-17^{2}+(0.10288876884) * \mathrm{IL}-17^{2} * \mathrm{AFP}$.
\end{abstract}

Conclusions: The circulatory IL-17 concentration is a predictor of subsequent HCC occurrence in liver cirrhotic patients. The combination of AFP and IL-17 is highly effective in predicting imminent HCC within 1 year.

Keywords: Immunology, Inflammation, Th17, Oncogenesis

*Correspondence: kunghao@gmail.com; chautingy@gmail.com ${ }^{1}$ Department of Medical Research, Taipei Veterans General Hospital, Taipei, Taiwan

${ }^{4}$ Liver Research Center, Chang Gung Memorial Hospital, Linkou, Taiwan Full list of author information is available at the end of the article

\section{Background}

Liver cirrhosis is a life-threatening disease responsible for more than 1,000,000 deaths annually worldwide [1]. Persistent or intermittent liver inflammation due to viral infection, alcohol toxicity, nonalcoholic steatohepatitis or autoimmune hepatitis can cause liver fibrosis and cirrhosis. One major sequela of liver cirrhosis is hepatocellular

(c) The Author(s) 2021. Open Access This article is licensed under a Creative Commons Attribution 4.0 International License, which permits use, sharing, adaptation, distribution and reproduction in any medium or format, as long as you give appropriate credit to the original author(s) and the source, provide a link to the Creative Commons licence, and indicate if changes were made. The images or other third party material in this article are included in the article's Creative Commons licence, unless indicated otherwise in a credit line to the material. If material is not included in the article's Creative Commons licence and your intended use is not permitted by statutory regulation or exceeds the permitted use, you will need to obtain permission directly from the copyright holder. To view a copy of this licence, visit http://creativecommons.org/licenses/by/4.0/. The Creative Commons Public Domain Dedication waiver (http://creativeco mmons.org/publicdomain/zero/1.0/) applies to the data made available in this article, unless otherwise stated in a credit line to the data. 
carcinoma (HCC), occurring at an annual rate of $2-5 \%$ [2]. Knowing exactly when HCC will occur is highly pertinent to the clinical care of cirrhotic patients. However, it seems unpredictable for individual patients. In some patients, HCC develops within 1 year, while in others, HCC never occurs in the patient's lifetime. In the past, noninvasive scores such as fibrosis-4 (FIB-4), AST to Platelet Ratio Index (APRI) and gamma-glutamyl transpeptidase-to-platelet ratio have been developed to estimate the severity of fibrosis $[3,4]$. These scores were subsequently used for the prediction of HCC [5-11], based on the rationale that the severity of fibrosis correlates with $\mathrm{HCC}$ risks. Noninvasive liver stiffness measurements were also used for the prediction of HCC [12] and posttreatment prognosis [13]. The organic anion transporter peptides (OATP) 1B1 and 1B3 has also been shown to be indicative of HCC recurrence after liver transplanation [14].

Alpha-fetoprotein (AFP) is a diagnostic biomarker of HCC and one of the most studied predictive biomarkers of imminent HCC that has high specificity [15-21]. However, HCC can still occur in patients without prominent AFP elevation, resulting in unsatisfactory sensitivity using AFP alone [15]. AFP-L3 and proteins induced by vitamin $\mathrm{K}$ absence (PIVKA-II) are two other biomarkers with clinical potential for HCC screening. However, the two biomarkers are rarely studied and used outside of Japan [22]. Thus, biomarkers and their optimum combinations for the prediction of subsequent HCC in liver cirrhotic patients remain an unmet medical need.

Recent pilot studies have unveiled the involvement of a proinflammatory cytokine, interleukin-17 (IL-17), in the pathogenesis of liver fibrosis, cirrhosis and autoimmune hepatitis. IL-17 is frequently elevated in patients with liver cirrhosis [23-26], autoimmune hepatitis [27], steatohepatitis [28, 29], and alcohol-related HCC [30]. Circulating and tissue-infiltrating Th17 cells were reported to correlate with the severity of liver inflammation in chronic hepatitis C patients [31]. Serum IL-17 levels were also observed to be in correlation with alanine aminotransferase (ALT) in an aggregated cohort of chronic hepatitis B patients and healthy controls [32], implying that ALT and IL-17 levels are both high in chronic hepatitis B patients and low in healthy controls. Another study showed that serum IL-17 was higher in cirrhotic hepatitis B patients than in asymptomatic hepatitis B carriers [33]. The fibrosis stages of patients were also positively correlated with IL-17 levels in the serum and liver [33]. A higher proportion of circulating inflammatory cells was observed in patients with higher IL-17 levels, in whom the histology activity index was also higher [34].

IL-17 has also been observed in other pilot studies on the prognosis of HCC. The serum levels of IL-17 in
HCC patients receiving surgical resections are indicative of poor time to progression and overall survival [35] as well as higher subsequent recurrence rates [36]. The intratumoral levels of IL-17 and its receptor are also associated with poorer postresection HCC recurrence and patient survival [35, 37]. Apart from HCC, IL-17 has been reported to be involved in other solid cancers such as non-small cell lung cancer [38] and medulloblastoma [39], suggesting its broad involvement in oncogenesis.

These pilot studies motivated us to investigate whether circulatory IL-17 concentrations could serve as a clinically useful biomarker for predicting HCC occurrence. Hence, we recruited a homogeneously cirrhotic, HCCnaïve patient cohort with extensive assessments of clinical variables, including plasma IL-17 concentrations and AFP. The patients were regularly followed after recruitment to monitor the occurrence of HCC at the earliest time possible.

\section{Methods \\ Patients}

This study was approved by Chang Gung Memorial Hospital, Taiwan, and conducted according to the 1975 Declaration of Helsinki. A total of 404 HCC-naïve, adult liver cirrhotic patients were recruited from three branches of Chang Gung Memorial Hospital in northern, central-northern and southern Taiwan. Patients with liver decompensation were excluded. All the patients provided informed consent. Cirrhosis was diagnosed by either (1) liver biopsy, or (2) ultrasound imaging in conjunction with endoscopy or transient elastography (FibroScan; Echosens, France). Basic demographic variables, viral etiology and general blood biochemistry measurements were documented at the time of patient recruitment (c.f. Table 1 for a complete list). This study was performed between 2013/1/1 and 2017/11/8. During this period, the patients were regularly followed every 3 months to monitor HCC occurrence. Chronic hepatitis B patients receive antiviral treatments if their HBV DNA levels were greater than $2000 \mathrm{IU} / \mathrm{mL}$. The recruited HCV patients were not treated initially until direct-acting antivirals (DAAs) were covered by national health insurance in Taiwan in 2017. Hepatocellular carcinoma was diagnosed by: (i) echoguided liver biopsy or fine-needle aspiration cytology, (ii) AFP $>200 \mathrm{ng} / \mathrm{mL}$, tumor $>2 \mathrm{~cm}$ and typical HCC characteristics in dynamic computed tomography, or (iii) typical HCC characteristics in both dynamic computed tomography and angiography. All HCC patients diagnosed during this study were at Barcelona Clinic Liver Cancer stage A.

Additionally, the surgically resected tumor tissue samples of 4 early-stage HCC patients were evaluated. The 
Table 1 Basic clinical and serum biochemistry variables and their association with circulatory IL-17 concentrations

\begin{tabular}{|c|c|c|c|c|c|}
\hline \multirow[t]{2}{*}{ Item } & \multirow[t]{2}{*}{ Values } & \multirow{2}{*}{$\begin{array}{l}\text { Beta } \\
\text { Coefficient }\end{array}$} & \multicolumn{2}{|c|}{ Confidence interval } & \multirow[t]{2}{*}{$P$} \\
\hline & & & Low & High & \\
\hline Patient \# & 404 & & & & \\
\hline IL-17 (ng/ml) & $5.57 \pm 18.74$ & & & & \\
\hline Age (years) & $59.37 \pm 10.94$ & 91.4 & -76.4 & 259.2 & 0.285 \\
\hline Gender-Male & $249(61.6 \%)$ & 1814.3 & -1956.2 & 5584.8 & 0.345 \\
\hline HBV positivity $^{\dagger}$ & $237(58.7 \%)$ & -1293.9 & -5019.2 & 2431.4 & 0.495 \\
\hline HCV positivity ${ }^{\ddagger}$ & $128(31.7 \%)$ & 2587.2 & -1350.0 & 6524.4 & 0.197 \\
\hline AST (IU/L) & $45.38 \pm 40.61$ & -2.9 & -48.2 & 42.5 & 0.900 \\
\hline $\operatorname{ALT}(I U / L)$ & $39.76 \pm 45.48$ & -13.7 & -54.2 & 26.8 & 0.506 \\
\hline Bilirubin (mg/dL) & $1.43 \pm 5.47$ & -7.4 & -344.1 & 329.3 & 0.965 \\
\hline AFP (ng/ml) & $8.84 \pm 28.99$ & 21.6 & -41.9 & 85.0 & 0.505 \\
\hline Albumin (g/dL) & $3.61 \pm 0.44$ & 1222.5 & -3006.3 & 5451.2 & 0.570 \\
\hline Total protein (g/dL) & $7.21 \pm 0.67$ & -455.5 & -3188.5 & 2277.5 & 0.743 \\
\hline $\mathrm{C} 3(\mathrm{mg} / \mathrm{dL})$ & $96.42 \pm 20.62$ & -73.7 & -163.1 & 15.8 & 0.106 \\
\hline $\mathrm{C} 4$ (mg/dL) & $19.68 \pm 8.40$ & -77.7 & -297.9 & 142.5 & 0.488 \\
\hline $\mathrm{TSH}(\mathrm{mU} / \mathrm{L})$ & $2.16 \pm 4.70$ & 29.0 & -360.5 & 418.5 & 0.884 \\
\hline Free T4 (ng/dL) & $1.07 \pm 0.26$ & -2422.4 & -9503.0 & 4658.2 & 0.502 \\
\hline Sugar AC (mg/dL) & $106.81 \pm 35.66$ & -14.1 & -65.8 & 37.7 & 0.593 \\
\hline Glycohemoglobin (\%) & $6.07 \pm 1.33$ & -447.7 & -1838.8 & 943.5 & 0.527 \\
\hline Insulin (mIU/L) & $11.33 \pm 12.31$ & -103.3 & -252.6 & 46.1 & 0.175 \\
\hline Insulin/Sugar & $0.38 \pm 2.21$ & -222.5 & -1128.2 & 683.2 & 0.629 \\
\hline HOMA-IR & $2.68 \pm 3.19$ & -243.9 & -868.3 & 380.4 & 0.442 \\
\hline Apo A1 (g/L) & $1.37 \pm 0.30$ & -4431.4 & $-10,512.7$ & 1649.8 & 0.153 \\
\hline Uric Acid (mg/dL) & $5.97 \pm 1.79$ & -695.8 & -1730.0 & 338.5 & 0.187 \\
\hline $\mathrm{HDL}(\mathrm{mg} / \mathrm{dL})$ & $48.70 \pm 16.27$ & 15.9 & -97.3 & 129.2 & 0.782 \\
\hline VLDL (mg/dL) & $20.67 \pm 13.88$ & -40.1 & -175.2 & 95.0 & 0.560 \\
\hline LDL (mg/dL) & $97.35 \pm 30.80$ & -30.7 & -91.3 & 29.8 & 0.319 \\
\hline Cholesterol (mg/dL) & $165.81 \pm 36.85$ & -26.5 & -76.8 & 23.8 & 0.302 \\
\hline Triglyceride (mg/dL) & $104.20 \pm 63.69$ & -8.5 & -37.7 & 20.6 & 0.565 \\
\hline Ferritin (ng/mL) & $274.01 \pm 445.64$ & 1.0 & -3.2 & 5.1 & 0.651 \\
\hline Ceruloplasmin (mg/dL) & $24.79 \pm 5.43$ & 15.1 & -327.7 & 358.0 & 0.931 \\
\hline Iron (ug/dL) & $119.29 \pm 55.86$ & 24.9 & -8.1 & 57.8 & 0.139 \\
\hline $\mathrm{TIBC}(\mathrm{ug} / \mathrm{dL})$ & $326.69 \pm 56.80$ & -13.2 & -45.7 & 19.3 & 0.424 \\
\hline UIBC (ug/dL) & $200.22 \pm 84.92$ & -14.3 & -42.0 & 13.3 & 0.309 \\
\hline
\end{tabular}

$\mp$ "HBV positivity" include (a) HBV without $\mathrm{HCV}, \mathrm{n}=219$; and (b) HBV, $\mathrm{HCV}$ co-infection, $\mathrm{n}=18$

₹ "HCV positivity" include (a) HCV without HBV, $\mathrm{n}=110$; and (b) HBV, HCV co-infection, $\mathrm{n}=18$

flowchart of this study is presented in Additional file 1: Figure S1.

\section{Quantifying circulatory IL-17 concentrations}

Peripheral blood samples were collected at patient recruitment, centrifuged and then stored in $-20{ }^{\circ} \mathrm{C}$ for the subsequent quantification of IL-17 concentrations using the Human IL-17A/F Heterodimer DuoSet Enzyme-Linked Immunosorbent Assay (ELISA) Kit
(DY5194-05), which was purchased from R\&D systems (Minneapolis, MN, USA).

\section{Immunohistochemistry staining of IL-17 and AFP in resected $\mathrm{HCC}$ tissues}

Immunohistochemistry staining of IL-17 and AFP was performed on surgically resected HCC tissues preserved in the formalin-fixed paraffin-embedded (FFPE) blocks and cut into sections with a thickness of $5 \mu \mathrm{m}$. The FFPE samples were deparaffinized, dehydrated and 
incubated with the appropriate antibodies (ab136668 and ab46799, Abcam, Cambridge, UK) for the staining.

\section{Results}

\section{IL-17 and AFP are present in HCC tissues}

We first evaluated whether IL-17 and AFP can be found in the tumor tissues of patients in Taiwan. We performed immunohistochemical (IHC) staining of IL-17 and AFP in surgically resected tumor tissues of 4 patients, and discovered that IL-17 and AFP were not homogeneously distributed in all patients we evaluated; rather, tissue of some patients showed signal of IL-17 but not AFP, while others showed signal of AFP but not IL-17. Images of such $\mathrm{IHC}$ results are presented in Additional file 1: Figure S2.

\section{Circulatory IL-17 concentration has no correlation with 31 demographic, metabolic and liver function variables}

The baseline clinical variables of the patient cohort are summarized in Table 1 . We first investigated the correlations between circulatory IL-17 concentrations and an extensive list of 31 baseline demographic variables and general biochemistry measurements pertaining to liver functions and metabolic disorders. IL-17 did not show a correlation with any of these variables (Table 1).

\section{Circulatory IL-17 is indicative of subsequent $\mathrm{HCC}$ at several cutoff points}

A preferable characteristic of a clinical biomarker is that it would remain effective in discriminating patients with different risk levels or disease severity levels in a wide range of cutoff points. We therefore evaluated IL-17 at various cutoff points with KaplanMeier visualization. The patients were stratified into 2, 3 and 4 equal-sized groups based on their plasma IL-17 concentrations. When the median value $(455 \mathrm{pg} / \mathrm{ml})$ was used as the cutoff point, patients with IL-17 $\geq$ the median had a significantly higher cumulative incidence of HCC than those with IL- $17<$ the median $(P=0.008$, Fig. 1a). When the patients were divided into tertiles (using the cutting values of 140 and $1105 \mathrm{pg} / \mathrm{ml}$ ), the cumulative incidence of tertile 1 (the group with the lowest IL-17 levels) was consistently lower than that of tertile 2 and tertile 3 (log-rank $P=0.004$ and 0.001 respectively, Fig. 1b). Patients in tertile 2 and tertile 3 showed non-overlapping Kaplan-Meier curves, yet the difference did not reach statistical significance $(P=0.653)$. When the patients were divided into quartiles (using cutoff values of 20, 455 and $1850 \mathrm{pg} / \mathrm{ml}$ ), patients in quartile $1 \sim 4$ showed four visually distinct curves, ordered from bottom to top in Fig. 1c. The cumulative HCC incidence of quartile 1 was significantly lower than that of quartile 3 and quartile 4
$(P=0.027$ and 0.005 respectively). Pairwise comparisons between the other strata do not show statistical significance, despite the visually distinct curves (Quartile 1 vs. $2 P=0.180$; Quartile 2 vs. $4 P=0.112$; Quartile 2 vs. $3 P=0.353$; Quartile 3 vs. $4 P=0.485$ ). The cumulative incidences of the patient strata are shown in Table 2 . The risk of $\mathrm{HCC}$ was relatively proportional to the IL-17 levels, facilitating the use of different cutoffs for different clinical purposes (Fig. 1a-c).

We also analyzed patient strata by AFP concentrations. When the patents were divided by the median $(3.9 \mathrm{ng} / \mathrm{ml})$, those with higher AFP had a significantly higher cumulative incidence of HCC $(P=0.003$, Fig. 1d). When the patients were stratified into tertiles by the cutoffs of 3.0 and $4.9 \mathrm{ng} / \mathrm{ml}$, the cumulative incidence of tertile 1 and tertile 2 was consistently lower than that of tertile $3(P=0.006$ and 0.013 respectively, Fig. 1e). When the patients were stratified into quartiles by the cutoffs of $2.7,3.9$ and $6.0 \mathrm{ng} / \mathrm{ml}$, the significance levels of difference in cumulative HCC incidence between quartiles 1 and 4, 2 and 4, and 3 and 4 were $0.003,0.001$ and 0.028 respectively (Fig. 1f). Pairwise comparisons between the other strata do not show statistical significance. The curves of quartile 1 and quartile 2 are intertwined.

Figure $1 \mathrm{f}$ and Table 2 show that AFP is useful for indicating a subset of high-risk patients whose AFP $\geqq$ $6.0 \mathrm{ng} / \mathrm{ml}$, corresponding to the $4^{\text {th }}$ quartile. We further asked that once these patients have been identified as high-risk patients due to their high AFP levels, how can the remaining patients be further stratified to reflect their different risk levels? In patients with AF $P<6.0 \mathrm{ng} / \mathrm{ml}$, the cumulative incidences of $\mathrm{HCC}$ at year 4 of patients IL- $17<$ median and $\geqq$ median are 0.03 and 0.08 respectively (Fig. 2b), suggesting that IL-17 levels can reflect the different $\mathrm{HCC}$ incidence in patients with low AFP. In contrast, the cumulative incidence of HCC at year 4 of patients with AF $P<$ median and $\geqq$ median are 0.05 and 0.06 respectively (Fig. $2 \mathrm{a}$ ), which are relatively close to each other.

\section{IL-17 concentrations were particularly effective in indicating HCC at one year}

We then analyzed the occurrence of $\mathrm{HCC}$ at different time points, including 1-, 2- 3- and 4-years after peripheral blood was drawn from the patients. It was found that the IL-17 concentrations could significantly classify patients with or without $\mathrm{HCC}$ at all these time points (Fig. 3a-d, $P=0.002,0.023,0.007$ and 0.004 for $1-4$ years respectively). Although the data suggest that IL-17 can reflect HCC occurrence in the next several years after baseline, the best performance was at year 1 , with the highest area under the 


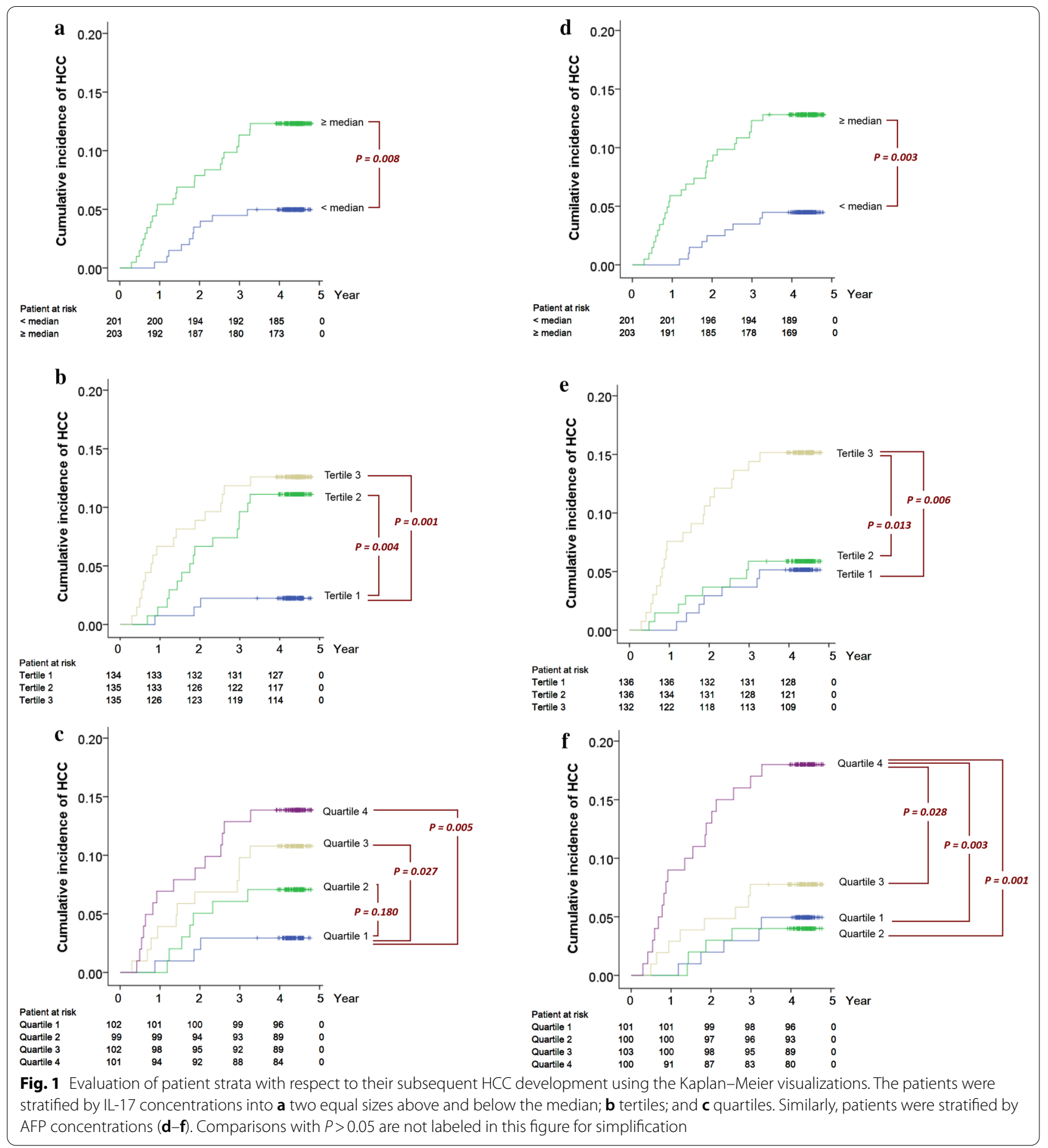

receiver operating characteristic curve $(\mathrm{AUC}=0.762)$ and the lowest $P$-value $(0.002)$. The results indicate that circulatory IL-17 concentrations were particularly effective for predicting imminent HCC, defined as the HCC occurrence within 1 year of sample collection.

\section{Investigating the synergistic effect of IL-17 and other} clinical variables

We then evaluated IL-17 and an extensive list of variables including viral etiology, gender (male, female), AFP, and general metabolic and liver function variables, for their association with imminent HCC using 
Table 2 Cumulative incidence of HCC in different patient groups stratified by IL-17 and AFP concentrations

\begin{tabular}{|c|c|c|c|c|c|c|c|c|c|c|}
\hline & \multicolumn{5}{|l|}{$\mathbb{I L}-17$} & \multicolumn{5}{|l|}{ AFP } \\
\hline & \multirow{2}{*}{$\begin{array}{l}\text { Cutoff } \\
(\mathrm{pg} / \mathrm{ml})\end{array}$} & \multicolumn{4}{|c|}{ Cumulative incidence at year } & \multirow{2}{*}{$\begin{array}{l}\text { Cutoff } \\
(\mathrm{ng} / \mathrm{ml})\end{array}$} & \multicolumn{4}{|c|}{ Cumulative incidence at year } \\
\hline & & 1 & 2 & 3 & 4 & & 1 & 2 & 3 & 4 \\
\hline$<$ Median & $<455$ & 0.000 & 0.035 & 0.045 & 0.050 & $<3.9$ & 0.000 & 0.025 & 0.035 & 0.045 \\
\hline$\geq$ Median & $\geq 455$ & 0.059 & 0.079 & 0.113 & 0.126 & $\geq 3.9$ & 0.059 & 0.089 & 0.123 & 0.128 \\
\hline Tertile 1 & $<140$ & 0.000 & 0.015 & 0.022 & 0.022 & $<3$ & 0.000 & 0.029 & 0.037 & 0.051 \\
\hline Tertile 2 & $<1105$ & 0.015 & 0.067 & 0.096 & 0.111 & $<4.9$ & 0.015 & 0.037 & 0.059 & 0.059 \\
\hline Tertile 3 & $\geq 1105$ & 0.076 & 0.089 & 0.119 & 0.126 & $\geq 4.9$ & 0.076 & 0.106 & 0.144 & 0.152 \\
\hline Quartile 1 & $<20$ & 0.000 & 0.020 & 0.029 & 0.029 & $<2.7$ & 0.000 & 0.020 & 0.030 & 0.050 \\
\hline Quartile 2 & $<455$ & 0.000 & 0.051 & 0.061 & 0.071 & $<3.9$ & 0.000 & 0.030 & 0.040 & 0.040 \\
\hline Quartile 3 & $<1850$ & 0.029 & 0.069 & 0.098 & 0.108 & $<6$ & 0.029 & 0.049 & 0.078 & 0.078 \\
\hline Quartile 4 & $\geq 1850$ & 0.090 & 0.089 & 0.129 & 0.143 & $\geq 6$ & 0.090 & 0.130 & 0.170 & 0.180 \\
\hline
\end{tabular}
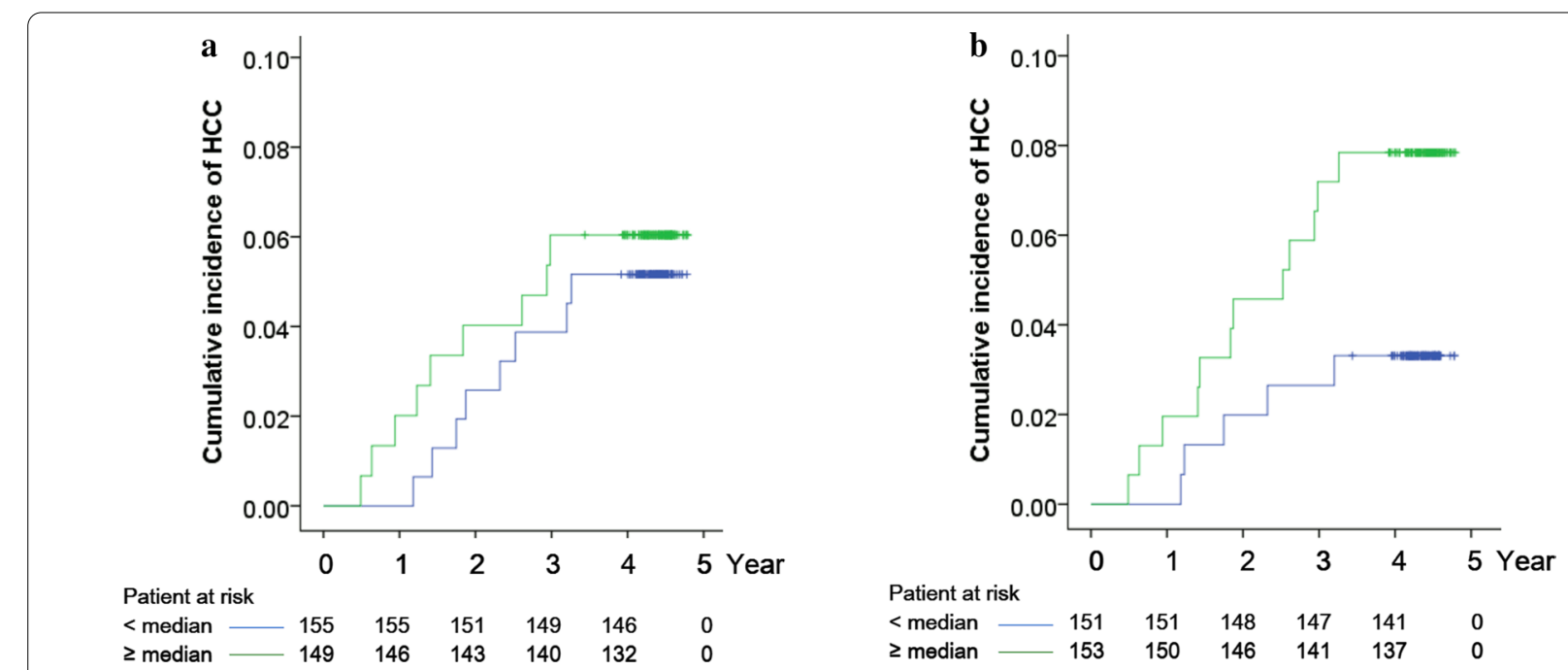

Fig. 2 The cumulative incidence of HCC in patients with AF $P<6.0 \mathrm{ng} / \mathrm{ml}$. a Patients were stratified by the median of AFP $(P=0.723)$. The cumulative incidence of HCC at year 4 of patients with AF $P<$ median and $\geqq$ median are 0.05 and 0.06 respectively. $\mathbf{b}$ Patients were stratified by the median of IL-17 $(P=0.086)$. The cumulative incidence of HCC at year 4 of patients with IL-17 < median and $\geqq$ median are 0.03 and 0.08 respectively

univariate logistic regression. Four variables, IL-17, age, HCV and AFP, were indicative of HCC (all $P<0.05$, Table 3 ). When the four factors were analyzed by multivariate logistic regression, all of them remained statistically significant. This finding showed that IL-17 (adjusted $P=0.008$, Table 3 ) and the other three factors are independent predictors of imminent HCC.

The coefficients of the four variables in the multivariate logistic regression analysis offered the following combination formula:

$$
0.021 * \mathrm{IL}-17+0.078 * \text { age }+1.449 * \mathrm{HCV}+0.012 * \mathrm{AFP}
$$

The synergistic effect determined by the above formula $(\mathrm{AUC}=0.866$ ), however, did not have a largeenough improvement with statistical significance from the predictive effect of IL-17 or AFP alone $(P=0.163$ and 0.445 , respectively, Fig. 3e).

We further evaluated the best possible performance for combining IL-17 and AFP. This time, we used an algorithm that we had developed in house, the generalized iterative modeling method (GIM), to find the optimum polynomial combination of biomarkers in terms of AUC [40]. The source code of GIM can be found on the following public-domain GitHub website: https://github.com/ khliang/GIM.

A risk score (R) was thus developed using this algorithm.

$$
\begin{aligned}
\mathrm{R}= & 2.6914 * \mathrm{IL}-17+(0.3909) * \mathrm{AFP}-(0.80812875) \\
& * \mathrm{IL}-17^{2}+(0.10288876884) * \mathrm{IL}-17^{2} * \mathrm{AFP}
\end{aligned}
$$



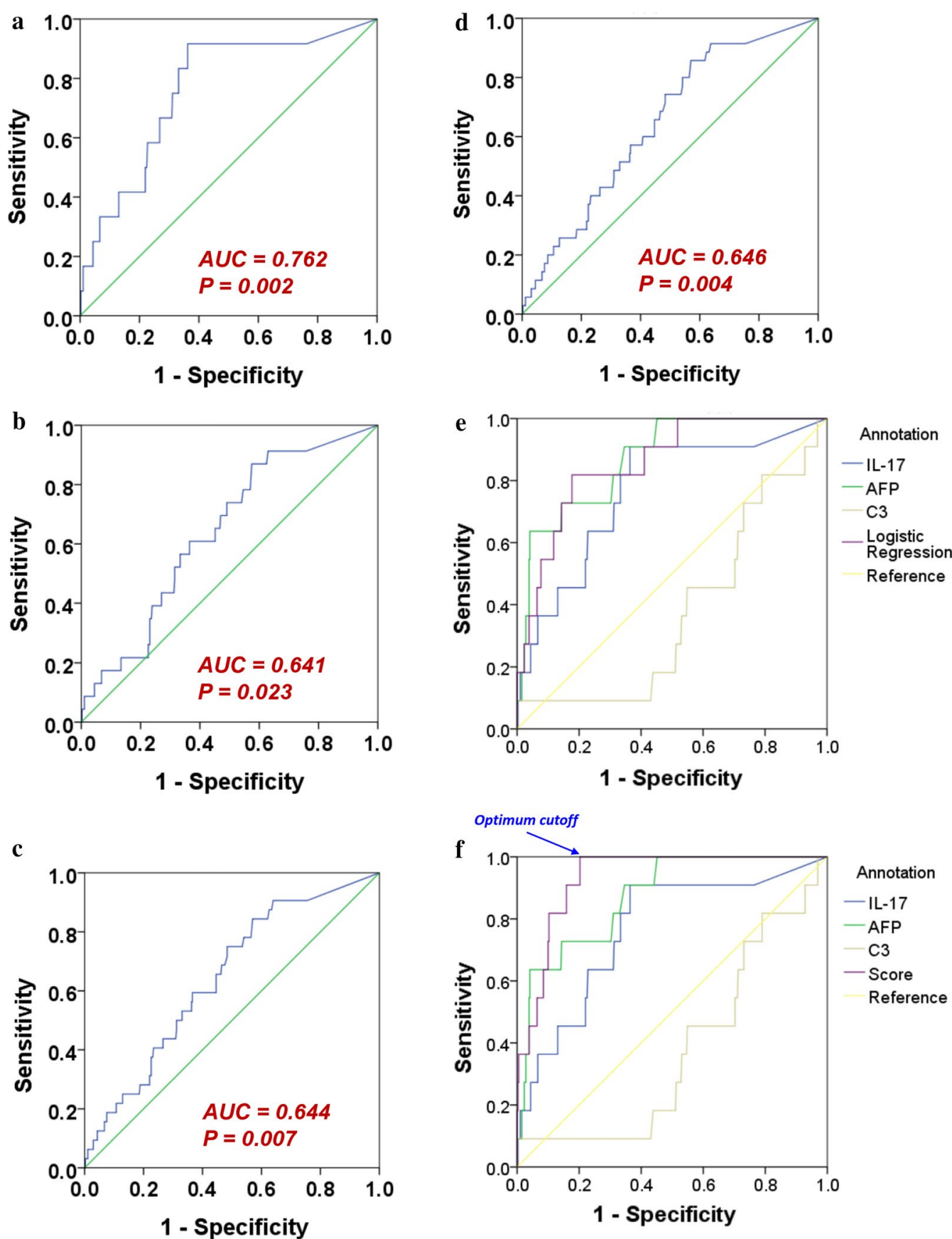

Fig. 3 The performance of biomarkers and their combinations for predicting the occurrence of HCC, shown by receiver operating characteristic curves. $\mathbf{a}$ The prediction by IL-17 alone of HCC events at 1 year; $\mathbf{b} 2$ years; $\mathbf{c} 3$ years $(n=404)$ and $\mathbf{d} 4$ years $(n=393 ; 11$ cirrhosis patients were censored in year 4). e The performance of predicting HCC events at 1 year using IL-17, AFP, C3 and the multivariate logistic regression Eq. (1). f The prediction of HCC events at 1 year using IL-17, AFP, C3 and the risk score combining IL-17 and AFP defined in Eq. (2)

The AUC of this risk score was 0.933 (confidence interval $=[0.893-0.972]$, Fig. 3f $)$. It had a significantly better performance than IL-17 alone $(\mathrm{AUC}=0.762$, $P=0.037)$. The performance was also better than that of AFP alone (AUC $=0.871)$ but did not achieve statistical significance $(P=0.255)$. The optimum cutoff, based on Youden's index [41], occurred at a score of 4.5072 (Fig. 3f). At this cutoff, the sensitivity and specificity 
Table 3 Univariate and multivariate analysis of variables associated with imminent HCC

\begin{tabular}{|c|c|c|c|c|}
\hline \multirow[t]{2}{*}{ Item } & \multirow[t]{2}{*}{ Odds ratio } & \multicolumn{2}{|c|}{ Confidence interval } & \multirow[t]{2}{*}{$P$} \\
\hline & & Low & High & \\
\hline \multicolumn{5}{|l|}{ Univariate analysis } \\
\hline IL-17 (pg/ml) & 1 & 1 & 1 & 0.004 \\
\hline Age (years) & 1.079 & 1.017 & 1.145 & 0.012 \\
\hline Gender-Male & 0.613 & 0.194 & 1.936 & 0.404 \\
\hline HBV & 0.341 & 0.101 & 1.152 & 0.083 \\
\hline $\mathrm{HCV}$ & 6.882 & 1.831 & 25.874 & 0.004 \\
\hline AST (IU/L) & 1.003 & 0.995 & 1.012 & 0.443 \\
\hline $\mathrm{ALT}(\mathrm{IU} / \mathrm{L})$ & 1.003 & 0.996 & 1.01 & 0.343 \\
\hline Bilirubin (mg/dL) & 0.89 & 0.369 & 2.151 & 0.797 \\
\hline $\operatorname{AFP}(\mathrm{ng} / \mathrm{ml})$ & 1.014 & 1.004 & 1.024 & 0.005 \\
\hline Albumin (g/dL) & 0.476 & 0.17 & 1.332 & 0.157 \\
\hline Total protein (g/dL) & 0.834 & 0.401 & 1.735 & 0.628 \\
\hline C3 (mg/dL) & 0.989 & 0.96 & 1.018 & 0.435 \\
\hline $\mathrm{C} 4(\mathrm{mg} / \mathrm{dL})$ & 0.949 & 0.867 & 1.037 & 0.248 \\
\hline $\mathrm{TSH}(\mathrm{mU} / \mathrm{L})$ & 0.448 & 0.179 & 1.121 & 0.086 \\
\hline Free T4 (ng/dL) & 0.099 & 0.003 & 3.519 & 0.205 \\
\hline Sugar AC (mg/dL) & 1.004 & 0.99 & 1.018 & 0.578 \\
\hline Glycohemoglobin (\%) & 1.206 & 0.864 & 1.684 & 0.270 \\
\hline Insulin (m|U/L) & 1.014 & 0.981 & 1.048 & 0.409 \\
\hline Insulin/sugar & 0.425 & 0.001 & 305.942 & 0.799 \\
\hline HOMA-IR & 1.1 & 0.976 & 1.241 & 0.118 \\
\hline Apo A1 (g/L) & 2.573 & 0.811 & 8.165 & 0.109 \\
\hline Uric acid (mg/dL) & 0.855 & 0.588 & 1.243 & 0.412 \\
\hline $\mathrm{HDL}(\mathrm{mg} / \mathrm{dL})$ & 0.977 & 0.935 & 1.02 & 0.285 \\
\hline $\operatorname{VLDL}(\mathrm{mg} / \mathrm{dL})$ & 1.011 & 0.978 & 1.045 & 0.516 \\
\hline $\mathrm{LDL}(\mathrm{mg} / \mathrm{dL})$ & 0.983 & 0.961 & 1.005 & 0.132 \\
\hline Cholesterol (mg/dL) & 0.993 & 0.977 & 1.008 & 0.346 \\
\hline Triglyceride (mg/dL) & 1.003 & 0.995 & 1.01 & 0.525 \\
\hline NonHDLC & 0.991 & 0.971 & 1.011 & 0.368 \\
\hline Ferritin (ng/mL) & 1 & 0.999 & 1.001 & 0.768 \\
\hline Ceruloplasmin (mg/dL) & 1.029 & 0.926 & 1.145 & 0.593 \\
\hline Iron (ug/dL) & 1.005 & 0.996 & 1.014 & 0.263 \\
\hline $\mathrm{TIBC}(\mathrm{ug} / \mathrm{dL})$ & 1.001 & 0.99 & 1.011 & 0.891 \\
\hline UIBC (ug/dL) & 0.997 & 0.988 & 1.007 & 0.591 \\
\hline \multicolumn{5}{|l|}{ Multivariate analysis } \\
\hline IL-17 (pg/ml) & 1 & 1 & 1 & 0.008 \\
\hline Age (years) & 1.081 & 1.008 & 1.161 & 0.030 \\
\hline $\mathrm{HCV}$ & 4.257 & 1.059 & 17.113 & 0.041 \\
\hline AFP & 1.012 & 1.002 & 1.023 & 0.024 \\
\hline
\end{tabular}

$P$ values smaller than 0.05 are shown in bold

were $100 \%$ and $79.9 \%$ respectively. We also applied this score to patient subsets of the two major etiologies: chronic hepatitis $B(n=237)$ and chronic hepatitis $\mathrm{C}(\mathrm{n}=128)$. The AUC were 0.950 [0.894-1] and 0.894
[0.825-0.964] for chronic hepatitis B and C patients respectively (both $P<0.001$ ).

\section{Discussion}

Liver fibrosis is a progressive disease which usually persists for decades and has multiple stages according to the definition by the Ishak or METAVIR systems [42]. Previously, non-invasive APRI and FIB-4 scores have been developed to indicate fibrosis stages, which naturally correlated with the HCC risks. More advanced stages correspond to higher HCC risks [5-11]. The current study addressed liver cirrhotic patients, corresponding to those in the stages 5 and 6 of the Ishak fibrosis staging system and stage 4 in the METAVIR staging system. HCC risks of liver cirrhotic patients have increased to a degree that imminent HCC is one major concern of patient care. Hence, additional biomarkers is required so as to provide high sensitivity and specificity of predicting imminent HCC in liver cirrhotic patients.

To date, ALT and AFP have been widely used for the assessment of liver disorders. ALT is released from the liver to the blood whenever there is liver damage. Thus, the circulatory levels of ALT are routinely used to indicate the extent of liver damage, acute liver inflammation and hepatitis $[4,43]$. AFP is an onco-fetoprotein produced by cancer cells. A wealth of literature has shown the usefulness of AFP for indicating imminent HCC [15-21]. In addition to the two biomarkers (ALT and AFP) attributed to hepatitis flares, IL-17 represents a distinct immunological aspect of the disease. IL-17 is a major cytokine mediating the Th-17 response. Based on recent pilot studies showing the correlation of high IL-17 levels with various liver-related clinical endpoints [28, 30,33, 35, 37, 44, 45], we performed a prospective cohort study, which showed that the circulatory IL-17 concentration can serve as a clinical biomarker for predicting imminent HCC. We showed that IL-17 can predict imminent HCC effectively, independent of age, viral etiology (i.e., $\mathrm{HCV}$ ) and AFP.

We explored two different methods of utilizing both AFP and IL-17, two distinct aspects of HCC biology. First, we evaluated a hierarchical patient stratification. Patients with AFP $\geqq 6.0 \mathrm{ng} / \mathrm{ml}$ are identified as at high risk of HCC. The remaining patients were further stratified by the medians of AFP and IL-17 subsequently to evaluate the performance of these two biomarkers. The cumulative incidence of the two patient strata by AFP are pretty close to each other, suggesting an unsatisfactory stratification (Fig. 2a). In contrast, when these patients were stratified by IL-17, those with higher IL-17 level have higher cumulative incidence of HCC (Fig. 2b), demonstrating the usefulness of IL-17 as the second biomarker in the hierarchical patient stratification. Second, we evaluated a polynomial model of 
predicting imminent $\mathrm{HCC}$ using AFP and IL-17. This model achieved a high area under the ROC of 0.933 in our patient cohort.

The predictability of IL-17 might be partly due to recently elucidated oncogenic mechanisms. IL-17 has been found to interact with EGFR, FGFR, NOTCH1 and C-type lectin signaling $[38,45,46]$. The oncogenic mechanisms of the IL-17 driven, IL-17/STAT3/ Notch1 [38] and IL-17/STEAP4/XIAP axes have been proposed, where IL-17 drives the intake of copper alongside the metalloreductase STEAP4 [47]. These mechanisms have been elucidated in solid cancers other than hepatocellular carcinoma. Thus, the exact oncogenic mechanism of IL-17 in HCC remains the goal of future investigations.

In this cirrhotic cohort, we observed that IL-17 concentrations did not correlate with an extensive list of 31 common clinical variables including AFP and ALT (Table 1). Correlation is a statistical method widely used for clinical studies. Correlation does not indicate causation, however, causation may manifest as numerical correlation between variables which offered clues for further investigations. Since there is no correlation found, no straightforward causation can be inferred between IL-17 and the studied variables.

Motivated by literature, we chose IL-17 as the main target of evaluation. This study is limited by the fact that no other cytokines were evaluated. Better biomarkers may be found among other cytokines which remained to be explored in future studies. Also, the current study is performed in patients in Taiwan. More studies are required to extrapolate the results into other populations in more geographical regions.

\section{Conclusion}

The circulatory IL-17 concentration is indicative of imminent HCC in liver cirrhotic patients. The combination of AFP and IL-17 can predict imminent HCC with a high AUC of 0.933.

\footnotetext{
Abbreviations

HCC: Hepatocellular carcinoma; FIB-4: Fibrosis-4; APRI: AST to Platelet Ratio Index; OATP: Organic anion transporter peptides; HDL: High density lipoprotein; HBV: Hepatitis B virus; HCV: Hepatitis C virus; AST: Aspartate aminotransferase; ALT: Alanine transaminase; AFP: Alpha-fetoprotein; AC: Ante cibum; T4: Thyroxin; Apo-A1: Apolipoprotein-A1; UA: Uric acid; LDL: Low density lipoprotein; VLDL: Very low density lipoprotein; TIBC: Total iron binding capacity; UIBC: Unsaturated iron binding capacity; C3: Complement component 3; C4: Complement component 4; BUN: Blood urea nitrogen; HOMA-IR: Homeostasis model assessment-estimated insulin resistance; PT: Prothrombin time; FFPE: Formalin-fixed paraffin-embedded; AUC: Area under the receiver operating characteristic curves; GIM: Generalized iterative modeling.
}

\section{Supplementary Information}

The online version contains supplementary material available at https://doi. org/10.1186/s12876-021-01761-1.

Additional file 1: Supplementary Figure 1. The flow chart of this study.

Supplementary Figure 2. The immunohistochemistry staining of IL-17 and AFP in tumor tissues.

\section{Acknowledgements}

The authors would like to thank Yi-Ting Liao, Ming-Yi Yen, Yu-Ru Liang, Yi-Wen Li, Yu-Chiao Chuang, Chung-Yin Wu, Fang-Yi He, Hui-Chin Chen, Ya-Ming Cheng, Yu-Jean Chen, Yen-Ling Chuang and Chien-Chih Wang for the excellent technical and administrative assistance. English editing by the Springer Nature Author Service is gratefully acknowledged

\section{Authors' contributions}

C-TY designed and supervised the study; KHL drafted the manuscript; M-WL, Y-HL, Y-DC, C-LL, W-RL, Y-HH, T-HW, R-NC and T-HH collected and analyzed the data. K-HL performed statistical analysis. All authors have approved the final version of the manuscript.

\section{Funding}

This work was supported by Grants from the Ministry of Science and Technology (MOST) in Taiwan (MOST 109-2314-B-075-057) for the staining of tumor tissues, and the Chang Gung Memorial Hospital Medical Research Program, Linkou (CIRPG3B0032) for the design, patient enrollment, data collection, analysis, interpretation and manuscript writing.

Availability of data and materials

The datasets of this study are available from the corresponding authors on reasonable requests.

\section{Declarations}

\section{Ethics approval and consent to participate}

This study was approved by the institutional review board of Chang Gung Memorial Hospital, Taiwan, and conducted according to the ethical guidelines of the 1975 Declaration of Helsinki. All the patients provided written informed consent.

\section{Consent for publication}

Not applicable.

\section{Competing interests}

The authors have declared that no conflict of interest exists.

\begin{abstract}
Author details
${ }^{1}$ Department of Medical Research, Taipei Veterans General Hospital, Taipei, Taiwan. ${ }^{2}$ Institute of Food Safety and Health Risk Assessment, National Yang Ming Chiao Tung University, Taipei, Taiwan. ${ }^{3}$ Institute of Biomedical Informatics, National Yang Ming Chiao Tung University, Taipei, Taiwan. ${ }^{4}$ Liver Research Center, Chang Gung Memorial Hospital, Linkou, Taiwan. ${ }^{5}$ Liver Research Unit, Keelung Chang Gung Memorial Hospital, No. 222, Maijin Road, Keelung, Taiwan. ${ }^{6}$ Community Medicine Research Center, Keelung Chang Gung Memorial Hospital, Keelung, Taiwan. ${ }^{7}$ Tissue Bank, Chang Gung Memorial Hospital, Tao-Yuan, Taiwan. ${ }^{8}$ Division of Hepatogastroenterology, Department of Internal Medicine, Kaohsiung Chang Gung Memorial Hospital, Kaohsiung, Taiwan. ${ }^{9}$ Molecular Medicine Research Center, Chang Gung University, Taoyuan, Taiwan. ${ }^{10}$ Liver Research Center, Chang Gung Memorial Hospital, 5, Fu-Shin street, Kuei-Shan District, Taoyuan, Taiwan.
\end{abstract}

Received: 25 September 2020 Accepted: 9 April 2021

Published online: 17 April 2021 


\section{References}

1. Mokdad AA, Lopez AD, Shahraz S, Lozano R, Mokdad AH, Stanaway J, Murray CJL, Naghavi M. Liver cirrhosis mortality in 187 countries between 1980 and 2010: a systematic analysis. BMC Med. 2014;12(1):1-24.

2. Fattovich G, Stroffolini T, Zagni I, Donato F. Hepatocellular carcinoma in cirrhosis: Incidence and risk factors. Gastroenterology. 2004:127(5):S35-50.

3. Vallet-Pichard A, Mallet V, Nalpas B, Verkarre V, Nalpas A, Dhalluin-Venier $\checkmark$, Fontaine $\mathrm{H}$, Pol S. FIB-4: An inexpensive and accurate marker of fibrosis in HCV infection. Comparison with liver biopsy and fibrotest. Hepatology. 2007:46(1):32-6.

4. Botros M, Sikaris KA. The de ritis ratio: the test of time. Clin Biochem Rev. 2013;34(3):117-30.

5. Abdelgawad IA. Clinical utility of simple non-invasive liver fibrosis indices for predicting hepatocellular carcinoma (HCC) among Egyptian patients. J Clin Pathol. 2014:68(2):154-60.

6. Guarino M, Sessa A, Cossiga V, Morando F, Caporaso N, Morisco F. Direct-acting antivirals and hepatocellular carcinoma in chronic hepatitis C: A few lights and many shadows. World J Gastroenterol. 2018:24(24):2582-95.

7. Kim JH, Lee M, Park SW, Kang M, Kim M, Lee SH, Kim TS, Park JM, Choi DH. Validation of modified fibrosis-4 index for predicting hepatocellular carcinoma in patients with compensated alcoholic liver cirrhosis. Medicine. 2018;97(48):e13438

8. Li X, Xu H, Gao P. Fibrosis Index Based on 4 Factors (FIB-4) predicts liver cirrhosis and hepatocellular carcinoma in chronic hepatitis C virus (HCV) patients. Med Sci Monit. 2019;25:7243-50.

9. Marasco G, Colecchia A, Silva G, Rossini B, Eusebi LH, Ravaioli F, Dajti E, Alemanni LV, Colecchia L, Renzulli M, et al. Non-invasive tests for the prediction of primary hepatocellular carcinoma. World J Gastroenterol. 2020;26(24):3326-43.

10. Paik N, Sinn DH, Lee JH, Oh IS, Kim JH, Kang W, Gwak G-Y, Paik Y-H, Choi MS, Lee JH, et al. Non-invasive tests for liver disease severity and the hepatocellular carcinoma risk in chronic hepatitis B patients with lowlevel viremia. Liver Int. 2017;38(1):68-75.

11. Zhu Y-F, Tan $Y-F$, Xu X, Zheng J-L, Zhang B-H, Tang H-R, Yang J-Y. Gamma-glutamyl transpeptidase-to-platelet ratio and the fibrosis-4 index in predicting hepatitis B virus-related hepatocellular carcinoma development in elderly chronic hepatitis B patients in China. Medicine. 2019:98(50):e18319.

12. Ravaioli F, Conti F, Brillanti S, Andreone P, Mazzella G, Buonfiglioli F, Serio I, Verrucchi G, Bacchi Reggiani ML, Colli A, et al. Hepatocellular carcinoma risk assessment by the measurement of liver stiffness variations in HCV cirrhotics treated with direct acting antivirals. Dig Liver Dis. 2018;50(6):573-9.

13. Colecchia A. Prognostic factors for hepatocellular carcinoma recurrence. World J Gastroenterol. 2014;20(20):5935.

14. Vasuri F, Golfieri R, Fiorentino M, Capizzi E, Renzulli M, Pinna AD, Grigion WF, D'Errico-Grigioni A. OATP 1B1/1B3 expression in hepatocellular carcinomas treated with orthotopic liver transplantation. Virchows Arch. 2011:459(2):141-6.

15. Bialecki ES, Di Bisceglie AM. Diagnosis of hepatocellular carcinoma. HPB (Oxford). 2005;7(1):26-34

16. Chun S, Rhie SY, Ki C-S, Kim JE, Park H-D. Evaluation of alpha-fetoprotein as a screening marker for hepatocellular carcinoma in hepatitis prevalent areas. Ann Hepatol. 2015;14(6):881-7.

17. Hann H-W, Fu X, Myers RE, Hann RS, Wan S, Kim SH, Au N, Xing J, Yang $\mathrm{H}$. Predictive value of alpha-fetoprotein in the long-term risk of developing hepatocellular carcinoma in patients with hepatitis B virus infection-results from a clinic-based longitudinal cohort. Eur J Cancer. 2012;48(15):2319-27.

18. Hsu C-Y, Liu P-H, Lee Y-H, Hsia C-Y, Huang Y-H, Lin H-C, Chiou Y-Y, Lee F-Y, Huo T-I. Using serum a-fetoprotein for prognostic prediction in patients with hepatocellular carcinoma: what is the most optimal cutoff? PLoS ONE. 2015;10(3):e0118825-e0118825.
19. Silva J, Berger N, Gamblin TC. Prognostic significance of baseline alphafetoprotein in hepatocellular carcinoma: systematic review and metaanalysis. HPB. 2017;19:S124.

20. Zhang J, Chen G, Zhang P, Zhang J, Li X, Gan DN, Cao X, Han M, Du H, Ye YA. The threshold of alpha-fetoprotein (AFP) for the diagnosis of hepatocellular carcinoma: a systematic review and meta-analysis. PLoS ONE. 2020;15(2):e0228857-e0228857.

21. Liang K-H, Zhang P, Lin C-L, Wang SC, Hu T-H, Yeh C-T, Su GL. Morphomic signatures derived from computed tomography predict hepatocellular carcinoma occurrence in cirrhotic patients. Dig Dis Sci. 2019;6:2130-9.

22. Kudo M. Clinical practice guidelines for hepatocellular carcinoma differ between Japan, United States, and Europe. Liver Cancer. 2015:4(2):85-95.

23. Esmailbeig M, Ghaderi A. Interleukin-18: a regulator of cancer and autoimmune diseases. Eur Cytokine Netw. 2017:28(4):127-40.

24. Fischer A. Human immunodeficiency: connecting STAT3, Th17 and human mucosal immunity. Immunol Cell Biol. 2008:86(7):549-51.

25. Naugler WE, Karin M. The wolf in sheep's clothing: the role of interleukin-6 in immunity, inflammation and cancer. Trends Mol Med. 2008;14(3):109-19.

26. Rutz S, Eidenschenk C, Ouyang W. IL-22, not simply a Th17 cytokine Immunol Rev. 2013;252(1):116-32

27. Longhi MS, Ma Y, Mieli-Vergani G, Vergani D. Aetiopathogenesis of autoimmune hepatitis. J Autoimmun. 2010;34(1):7-14.

28. Gomes Ana L, Teijeiro A, Burén S, Tummala Krishna S, Yilmaz M, Waisman A, Theurillat J-P, Perna C, Djouder N. Metabolic inflammation-associated IL-17A causes non-alcoholic steatohepatitis and hepatocellular carcinoma. Cancer Cell. 2016:30(1):161-75.

29. Chackelevicius CM, Gambaro SE, Tiribelli C, Rosso N. Th17 involvement in nonalcoholic fatty liver disease progression to non-alcoholic steatohepatitis. World J Gastroenterol. 2016;22(41):9096

30. Ma H-Y, Yamamoto G, Xu J, Liu X, Karin D, Kim JY, Alexandrov LB, Koyama $Y$, Nishio T, Benner C, et al. IL-17 signaling in steatotic hepatocytes and macrophages promotes hepatocellular carcinoma in alcohol-related liver disease. J Hepatol. 2020;72(5):946-59.

31. Chang Q, Wang Y-K, Zhao Q, Wang C-Z, Hu Y-Z, Wu B-Y.Th17 cells are increased with severity of liver inflammation in patients with chronic hepatitis C. J Gastroenterol Hepatol. 2012;27(2):273-8.

32. Shi MIN, Wei JUE, Dong J, Meng W, Ma J, Wang T, Wang NA, Wang Y. Function of interleukin-17 and -35 in the blood of patients with hepatitis B-related liver cirrhosis. Mol Med Rep. 2014;11(1):121-6.

33. Du W-J, Zhen J-H, Zeng Z-Q, Zheng Z-M, Xu Y, Qin L-Y, Chen S-J. Expression of interleukin-17 associated with disease progression and liver fibrosis with hepatitis B virus infection: IL-17 in HBV infection. Diagn Pathol. 2013;8(1):1-7.

34. Zhang J-Y, Zhang Z, Lin F, Zou Z-S, Xu R-N, Jin L, Fu J-L, Shi F, Shi M, Wang $\mathrm{H}-\mathrm{F}$, et al. Interleukin-17-producing $\mathrm{CD} 4+\mathrm{T}$ cells increase with severity of liver damage in patients with chronic hepatitis B. Hepatology. 2009;51(1):81-91.

35. Liao R, Sun J, Wu H, Yi Y, Wang J-X, He H-W, Cai X-Y, Zhou J, Cheng Y-F, Fan $J$, et al. High expression of IL-17 and IL-17RE associate with poor prognosis of hepatocellular carcinoma. J Exp Clin Cancer Res. 2013;32(1):3.

36. Wu J, Du J, Liu L, Li Q, Rong W, Wang L, Wang Y, Zang M, Wu Z, Zhang $Y$, et al. Elevated pretherapy serum IL17 in primary hepatocellular carcinoma patients correlate to increased risk of early recurrence after curative hepatectomy. PLoS ONE. 2012:7(12):e50035.

37. Zhang J-P, Yan J, Xu J, Pang X-H, Chen M-S, Li L, Wu C, Li S-P, Zheng L. Increased intratumoral IL-17-producing cells correlate with poor survival in hepatocellular carcinoma patients. J Hepatol. 2009;50(5):980-9.

38. Wang R, Yang L, Zhang C, Wang R, Zhang Z, He Q, Chen X, Zhang B, Qin Z, Wang $L$, et al. Th17 cell-derived IL-17A promoted tumor progression via STAT3/NF-KB/Notch1 signaling in non-small cell lung cancer. Oncolmmunology. 2018:7(11):e1461303.

39. Zhou P, Sha H, Zhu J. The role of T-helper 17 (Th17) cells in patients with medulloblastoma. J Int Med Res. 2010;38(2):611-9.

40. Huang Y-H, Liang K-H, Chien R-N, Hu T-H, Lin K-H, Hsu C-W, Lin C-L, Pan T-L, Ke P-Y, Yeh C-T. A circulating MicroRNA signature capable of assessing 
the risk of hepatocellular carcinoma in cirrhotic patients. Sci Rep. 2017;7(1):1-12.

41. Youden WJ. Index for rating diagnostic tests. Cancer. 1950;3(1):32-5.

42. Ishak K, Baptista A, Bianchi L, Callea F, De Groote J, Gudat F, Denk H, Desmet $\mathrm{V}$, Korb G, MacSween RNM, et al. Histological grading and staging of chronic hepatitis. J Hepatol. 1995;22(6):696-9.

43. Sookoian S. Alanine and aspartate aminotransferase and glutaminecycling pathway: their roles in pathogenesis of metabolic syndrome. World J Gastroenterol. 2012;18(29):3775.

44. Hammerich L, Heymann F, Tacke F. Role of IL-17 and Th17 cells in liver diseases. Clin Dev Immunol. 2011;2011:1-12.

45. Li X, Bechara R, Zhao J, McGeachy MJ, Gaffen SL. IL-17 receptorbased signaling and implications for disease. Nat Immunol. 2019:20(12):1594-602.
46. Wang C, Zhang C-J, Martin BN, Bulek K, Kang Z, Zhao J, Bian G, Carman JA, Gao J, Dongre A, et al. IL-17 induced NOTCH1 activation in oligodendrocyte progenitor cells enhances proliferation and inflammatory gene expression. Nat Commun. 2017;8(1):1-16.

47. Liao Y, Zhao J, Bulek K, Tang F, Chen X, Cai G, Jia S, Fox PL, Huang E, Pizarro TT, et al. Inflammation mobilizes copper metabolism to promote colon tumorigenesis via an IL-17-STEAP4-XIAP axis. Nat Commun. 2020;11(1):900-900.

\section{Publisher's Note}

Springer Nature remains neutral with regard to jurisdictional claims in published maps and institutional affiliations.
Ready to submit your research? Choose BMC and benefit from:

- fast, convenient online submission

- thorough peer review by experienced researchers in your field

- rapid publication on acceptance

- support for research data, including large and complex data types

- gold Open Access which fosters wider collaboration and increased citations

- maximum visibility for your research: over 100M website views per year

At BMC, research is always in progress.

Learn more biomedcentral.com/submissions 